\title{
Cross-Cultural Challenges in Web-Based Instruction
}

\author{
Bolanle A. Olaniran* \\ Department of Communication Studies \\ Texas Tech University \\ 2500 Broadway, Lubbock, TX 79409, USA \\ E-mail: b.olaniran@ttu.edu
}

\author{
Natasha B. Rodriguez \\ Department of Communication Studies \\ Texas Tech University \\ 2500 Broadway, Lubbock, TX 79409, USA \\ E-mail: natasha.rodriguez@ttu.edu
}

\section{Indi M. Williams}

Mary Lou Fulton Institute \& Graduate School of Education

Arizona State University

Tempe, AZ 85287-0211, USA

E-mail: indi.m.williams@gmail.com

*Corresponding author

\begin{abstract}
Web Based Instruction (WBI) possesses great potential for delivering e-learning solutions into Lower Economically Disadvantaged Countries (LEDCs) and organizations with virtual networks of employees spread across the globe. However, these e-learning solutions are not without cross-cultural challenges. In order to adequately utilize these resources, it is imperative that developers and organizations understand how to address differences in norms, preferences and values of culturally diverse individuals when designing WBI. When instruction does not effectively address student needs, users can be distracted, or even discouraged, from completing instruction and quite possibly reject the technology through which the instruction is delivered. The purpose of this paper is to present an examination of cross cultural challenges in implementing WBI, through a discussion of Hofstede's (1980) cultural dimensions, cultural technology perceptions, language barriers and user needs. The paper concludes with a discussion the implications of WBI and future trends in WBI design.
\end{abstract}

Keywords: Individualism, Masculinity, Power Distance, Uncertainty Avoidance, Web-Based Instruction.

Biographical notes: Bolanle A. Olaniran is a Professor and Interim Chair in the Department of Communication Studies at Texas Tech University. His research includes: Communication technologies and Computer-Mediated Communication, Organization communication, Cross-cultural communication, and Crisis Management and Communication. He has authored several journal articles and book chapters in national and international interdisciplinary publications. 


\begin{abstract}
Natasha Brooke Rodriguez is a graduate teaching assistant, pursuing her Master's in Communication Studies at Texas Tech University. Her research interests include Computer-Mediated Communication, eLearning/virtual learning communities, and Domestic Violence

Indi Marie Williams received her Master's in Communication Studies from Texas Tech University, Lubbock, Texas and her bachelors from the University of Texas Austin. She is currently a doctoral student in Educational Technology at Arizona State University. Her research interests include virtual learning communities, web 2.0, Globalization and online culture.
\end{abstract}

\title{
1. Introduction
}

Web Based Instruction (WBI), commonly referred to as e-learning, is a form of instruction that entails the delivery of learning and curriculum materials through Internet Communication Technologies (ICT) to individuals in distant or remote locations. This form of instruction is readily being utilized in various regions around the world. In particular, e-learning is believed to be a possible solution to deliver instructional content to Lower Economically Developed Countries (LEDCs) in order to address extremely low education and technical literacy rates in many diverse parts of the globe. However, in order to realize e-learning objectives, it is also important to address its limitations. Most e-learning solutions implemented in Economically Developed Countries (EDC) by nature assume that all learners are self-motivated to be in control of their own learning. This however, is not always the case. Cultural norms, traditions and values, greatly influence both learning decisions, and learning outcomes (Olaniran, 2007a). These factors not only increase uncertainty within the e-learning environment, but they also heighten the need for a culture centered design and development of the WBI technology.

Similarly, organizations employing the use of virtual resources implement WBI technologies to foster organizational goals, idea generation and knowledge creation. Thus, as more organizations begin to use ICT in business and continue to employ individuals from various parts of the world, they are faced with similar cultural challenges as to how to design and implement technology that will foster cross-cultural communication and increase productivity without hampering organizational unity. However, a simple focus on organizational goals, in the absence of cultural implications, is not a viable solution (Olaniran, 2007a, 2007b). In order to increase the success of e-learning solutions, different designs must be developed to enhance the learning environment and create a meaningful learning experience for all employees involved. Subsequently, for these changes to occur, a deeper understanding of cross-cultural differences is essential.

Although the use of the Internet for collaborative learning is growing at an amazing rate, there remain both technical and socio-cultural challenges to implementation. Schneckenberg (2009) argues that underlying challenges to the acceptance and adoption of eLearning in higher education are due to "structural peculiarities of universities and cultural barriers" (p. 414). Unfortunately, these difficulties affect both the novice and the long term user alike. Scholars have reported that some learners are even frustrated with the technology early in the course, and that the technology predisposes these learners to information overload (e.g., Attack, 2003; Baruzzo, Dattolo, Pudota, \& Tasso, 2009; Niedderhauser, Bigley, Hale, \& Harper, 1999). Other problems with WBI include: uncertainty as to when and how to complete assignments, feeling out of place with class discussion, feeling a sense of isolation from 
other students and displaying an unwillingness to contact instructors, even when it is evident that a student needs help. At the same time, the asynchronous learning environment, commonly found in WBI, also creates problems with students who are unable to employ effective time management skills (Attack, 2003; Liao \& Huang, 2009; Milstead \& Nelson, 1998; Niederhauser et al., 1999). Furthermore, value preferences, instructor roles, language barriers and societal norms all greatly affect e-learning acceptance and ultimate use (Olaniran, 1993, 2007a).

A critical challenge of the implementation of WBI, however, lies in the installation of these solutions within varied and distinct cultures, whose differences may potentially cause these "Westernized" technologies to be viewed as an invasion to their cultural values, norms and identity. In order to address these cross-cultural issues, it is essential to understand how culture plays a critical role in determining the four aspects of technology (a) if and how it is adopted; (b) how it is used; (c) how messages are structured and interpreted; and, (d) the structure of learning activities. Therefore, it is imperative to match learning content to the needs of the learners such that this content is designed based upon a clear understanding of its cultural implications.

The goal of this paper is to examine the cross-cultural challenges of WBI and to present a picture of technology through the examination of Hofstede's (1980) cultural dimensions, the propensity to use WBI technologies, perceptions of culture and technology, language barriers, and media choice as directed through cultural preferences. The paper concludes with a discussion of e-learning solutions in the workplace, implications and future trends in WBI design.

\section{Theoretical Framework}

\subsection{Web-Based Instruction and Culture}

In order to begin a discussion of Web Based Instruction, it is important to be cognizant of the role of geographical distance and culture. It is only with this knowledge that the accommodation of the different learning needs for different cultures can be addressed. Additionally, cross-cultural understanding allows for the promotion of equitable learning outcomes for targeted learners, and the support of education and technological literacy that improves socio-economic opportunities in developing nations. In general, geographic cultures have significant implications for the adoption of web based instruction (WBI) and technological innovation. However, it is also important to look at the dimensions of cultural differences to understand exactly how culture affects the usage, or technology within a society.

The four dimensions of cultural variability consist of power distance, uncertainty avoidance, individualism, and masculinity (Hofstede, 1980, 2001; See also Dunn \& Marinetti, 2002 overview of cultural value orientations and cultural dimensions). More than arbitrary categories of culture, these four dimensions result from data collected from fifty countries and three world regions (Hofstede, 1980, 1983). Past research has used these dimensions to operationalize cultural differences and their effects on intercultural communication interactions (Gudykunst, Chua \& Gray, 1987; Olaniran, 1996; Olaniran \& Stewart, 1996; Roach \& Olaniran, 2001; Sanchez-Franco, Martinez-Lopez, \& MartinVelicia, 2009).

Power distance, is defined as "the extent to which the less powerful members of institutions and organizations accept that power is distributed unequally" (Hofstede \& 
Bond, 1984, p. 418). Uncertainty avoidance describes "the extent to which people feel threatened by ambiguous situations and have created beliefs and institutions that try to avoid these" (Hofstede \& Bond, 1984, p. 419). Of these dimensions, the most frequently discussed, when it comes to culture and online learning is the individualistic/collectivistic dimension (Tapanes, Smith, \& White, 2009). Individualism-collectivism acknowledges the fact that in individualistic cultures, "people are supposed to look after themselves and their family only," while in collectivistic cultures, "people belong to in-groups, or collectivities, which are supposed to look after them in exchange for loyalty" (Hofstede \& Bond, 1984, p. 419). The Masculinity dimension addresses cultures in which "dominant values in society are success, money and things," while femininity refers to cultures "in which dominant values are caring for others and quality of life" (Hofstede \& Bond, 1984, p. 419-420). All of these dimensions have been directly linked to e-learning (Olaniran, 2007a). Furthermore, it is accepted that the cultural motivations of individuals play a significant role while representing the foundation of e-learning (Henning, 2003; Schneckenberg, 2009; Van Dam \& Rogers, 2002).

Using Hofstede's (1980) dimensions of cultural variability, Van Dam \& Rogers (2002) discuss design elements and actions for the adaptation of e-learning. Within the uncertainty avoidance dimension, e-learning issues of security and risk are of primary concern (see also Tapanes et al. 2009). For instance, e-learning is expected to be seen in high-risk countries (i.e., culture) as something intriguing and potentially fun, motivational and interesting; while in a high security country it can be perceived as dangerous, or downright risky. Power distance, which is a measure of inequality in a given culture, suggests that in high equality cultures, concerns arise as to the expectations that knowledge is being shared or distributed equally. In a high status culture, however, expectations call for "telling" strategies where the knowledgeable are required to teach whatever is needed to be learned (see also Sanchez-Franco et al., 2009).

Specifically, Lee and Johari (2004) examine WBI use in China (i.e., a high power distant culture) and note that the technology platform introduces a "Westernized, liberal democratic" method of communication, which in essence, biased users toward these set of values (see also Tapanes et al., 2009; Thurber, Pope, \& Stratton, 2003). Individualism then suggests that in a high independence culture, there is a sense of controlling one's destiny as far as career and work choices. But in a collectivistic culture (group oriented) the success of the group is more important. The Masculine-feminine dimension describe the idea of work-life balance in which work focus countries require achievement and recognition, (i.e., people live to work), whereas in a life focus culture, work related issues including learning must be performed within the context of life (i.e., people work to live).

Despite decentralization and opportunity for increased participation facilitated by WBI technologies in certain cultures, most cultures still remain high context and power distant (e.g., Japanese culture). In a high-context culture, information is internalized in persons or situations, while power distant cultures recognize or accept the fact that power is not evenly distributed (see Hall, 1976; Hofstede, 1980). These cultural categories have implications for implicit and explicit communication tendencies and the general propensity to use technology in global education and e-learning (see also Olaniran, 2009). For instance, Chinese students "are more silent, passive, diligent, formal, and contentoriented in discussions; deferent to teacher; have concern for others; and worry about losing face" (Zhu, Valcke, Schellens, 2009, p. 34). Zhu et al. (2009) noted Western cultures generate very different educational philosophies and beliefs in comparison to Asian cultures, which can affect the acceptance of WBI technology. Therefore, cultural factors tend to influence how individuals use or view communication technologies and the interpretations drawn from messages distributed through them. Devereaux and 
Johansen (1994) argued that it might be difficult to get people to use certain technology such as Computer-Mediated Communication (CMC) systems in power distant cultures where status dictates every aspect of interpersonal communication. Therefore, technology transfer, the likes of WBI technologies, are not value free but instead value laden (Aydin, McIsaac, \& Johari, 2004; Lee \& Johari, 2004; Olaniran, 2007a, 2007b, 2009; Thurber, et al., 2003). Nevertheless, others (e.g., Ess, 2002) have argued the "soft deterministic" effect of technology, which implies that every culture tends to find ways to adapt technologies to their cultural communication and none disputed the fact that cultural differences affect technology adoption and use. For instance, in African cultures, where significant emphasis is placed on relationships, it was found that when e-mail was used for local communications, users often follow online communication with a telephone call as a back up medium to ensure that the message had been received (McConnell, 1998). Also, Japanese designers attempt to deal with their culture by acknowledging that not all types of communication can be supported by communication technology. Heaton (1998) addresses the issue of culture by suggesting that if communication technologies are to be useful in Japan, it is important that a familiar sense of atmosphere or feeling must be conveyed through the system. To this end, she recommends that online groups should first meet face-to-face to establish a trust environment (see also Ess, 2002).

In general, a key challenge in WBI or e-learning centers around the fact that there does not appear to be a technological or cultural fit in the diffusion of some westernized technologies (e.g., Green \& Ruhledder, 1995; Mesdag, 2000; Olaniran, 2007a; 2009). Specifically, learning content in web based environments need to match the needs of users. Olaniran (2009) argues that "effort must be focused to ensure that all learners have their needs met, and more importantly, that learning takes place" (p. 269). Thus, WBI that fails to account for or resolve cultural problems by accounting for differences in values, structures, and learning activities might fail miserably (see also Khalil \& Seleim, 2009; Zhu et al., 2009; Olaniran, 2009).

\subsection{The Propensity to Transfer and Use Technology}

The propensity to use any communication technology, and especially WBI, starts with access to technology and the willingness to use it (Olaniran, 1993). A study on attitude and perceptions of e-learning found easy accessibility as the top motivators for students using e-learning at $47 \%$, while course relevance to future career and user friendliness were next at 29\% and 24\% respectively (Vaughan \& MacVicar, 2004). A factor contributing to technology access in LEDCs is "technology transfer." Bozeman (2000) argues that technology transfer is based on cost and benefits, and usually the transfer exists only when the benefits outweigh the cost. This is significant in the race to bridge the digital divide between economically developed countries (EDCs) and lower economically developed countries (LEDCs). There is a significant disparity between EDCs, where access to internet resources is a fairly common occurrence, versus LEDCs, who tend to be poorer and thus have limited access to the web (Lee \& Johari, 2004; Olaniran, 2008). Also, major communication technology advances occur in developed countries, such that there are disparities in access to this technology in LEDCs when compared with EDCs (see also Olaniran, 2009).

With WBI, the implications extend beyond mere access as there is also an issue of file compatibility (Hill, 2002) and broadband concerns. For instance, the web allows for multimedia files which may or may not be accessible to learners depending on the mode of access. At times, users may have to travel several miles to access WBI. This, however, does not always bode well with motivating potential users to consider using the technology. Because of various access problems with the web, there exist challenges with 
frequency of use and apprehension in the use of the technology. Furthermore, there is a challenge with technical literacy resulting from the lack of comprehension of basic commands that can facilitate adoption leading to continued use of the technology (Olaniran, 1993). At the same time, one needs to realize that because the majority of the WBI content emanates from EDCs, it is designed with this "primary" culture audience in mind, and when the content is transferred across cultural borders, the users in these cultures may or may not be able to successfully adapt to the content as intended. To this end, Lee and Johari (2004) asked that one consider the following unanswered questions, does the use of WBI leads to cultural acculturation? And, what kinds of impacts do the "Westernized icons and graphics" have on the adopting cultures? These are important questions as we move forward in exploring the impacts of WBI across contexts.

\subsection{Culture and Technology Perceptions}

Along with general access, culture plays a significant role in how people perceive technology, as indicated earlier. For instance, the difference between what a new technology such as E-learning has to offer, and the traditional (i.e., local cultural) approach is not to be taken lightly. People fear new things, despite the fact that change itself is a constant in human life. However, in high power distance cultures, individuals tend to see technology systems as threatening to their traditional learning methods. As a result, these cultures are more afraid of technology, and consequently their reaction in using these technologies demonstrates their apprehension. For instance, it has been pointed out that Chinese systems of education focus on test-taking, hence, for WBI to be effective, a change must be instituted into systems that call for self reliance and critical thinking and problem solving (Lee \& Johari, 2004; Leu, 2001; Lin \& Jiang, 2003). Henning (2003) also provided a similar glimpse of cultural effects in WBI when she looked at interaction with technology among two users in South Africa.

When I wrote my first discussion posting I was so afraid. Would this get to others? Will they laugh, what will Prof say? ... I feel I have not the same control as before. I type and I read and I am scared to click because when I do that I feel I am falling down (Henning, 2003; p. 308).

From this example one can see the terrifying feelings that emerge from the perception of loss of control related to the use of a different mode of learning. These feelings are real to the people from this culture, as they have certain ideals and expectation of how learning ought to occur, and when that is not the case, people become uncomfortable (see also Olaniran, 2009). As Henning (2003) interprets this information, she concludes that users were having inner struggles about who is in charge of the learning.

The idea of collective in collectivistic cultures, which involves the need to be part of a group rather than an individual, comes into play when different cultures view or use WBI. Zhu, Valcke, and Schellens (2009) examined cultural differences between Westernized students (i.e., individualistic) and Chinese students (i.e., collectivistic) and concluded that online activities should avoid putting Chinese students on the spot as individuals because the students "may not be able to present themselves as knowledgeable" (Zhu et al., 2009, p. 42), due to their collectivistic nature. The implication here is that online activities should be culturally tailored (Zhu et al., 2009). In addition, people from collectivistic cultures tend to seek connections, or relationships, that provide them with a sense of how they connect with others. Henning (2003) found that when some of her participants viewed web pages for information, they stressed that 
all they saw were basically words and graphics, but there was no sense of someone else being on the other side to invite them into their homes, and physically interact with them. Simply put, the personal feelings and connections were not there, and this affected their willingness to participate (see also Olaniran, 2009).

This idea speaks in general to the lack of connection that is often attributed to CMC technology in general. For instance, time can pass with little, or no, correspondence from other learners, thus creating feelings of isolation. At the same time, the perception of isolation can result in "disconnection" leading to "loosing track" of the interactions and conversations during WBI. This may further lead to the need to "catch up" with the subject matter of the conversation, a task that can become overwhelming or daunting, particularly in an unfamiliar e-learning environment (Hill, 2002; Neuman, 1998). There is additional apprehension facing WBI participants when it comes to performance evaluation. Some participants are hesitant about their course performance grades. They stress the need for a trial run, and regular assurances that they are doing well. However, and more importantly, these students have a need for the course facilitator, or instructor, to encourage and reassure them that everything will be all right, as stressed in the next statement from a principal participating in a e-learning environment.

I have learned something, but not a lot. What I think they [instructors] should do is to teach us how to behave in this sort of set-up before we do a course. I mean not just computers, but the real e-learning thing. By the time I got used to it, it was too late and I think I will fail this one. I still dream of a book and a neat study guide and I am not happy with professor...she thinks we are Americans who breathe through the lungs of the web (Henning, 2003; p. 310).

\subsection{Language}

Central to cultural challenges in WBI is the issue of language, where it is noted that the majority of Internet content is primarily in English (Barron, 2000; Olaniran, 2007a; Tapanes, 2009; Van Dam \& Rogers, 2002). Meanwhile, non- English speaking individuals may feel that technology has nothing to offer them. Even in situations where people speak, or understand, English, its use is limited to certain contexts. For instance, it is not uncommon to find people in other cultures who restrict their English usage to work, schools and other formal business settings, while, for the most part, local language and other dialects still characterize most of their daily communication encounters. Furthermore, learning in a second language through school is quite different from foreign language learning itself (Collier, 1995; Williams, Warren, \& Olaniran, 2009). Also, it is documented that as much as $36 \%$ of Internet users indicated that they would prefer to use a language online that differs from English (Van Dam \& Rogers, 2002). In a study looking at the WBI, an e-learning program offered by Cisco in English, students who use English as a second language indicated that they prefer their instructors to first overview the content of the chapter before assigning it to be read (Selinger, 2004). In a web-based instructional curriculum, it stands to reason that when the content is provided in languages other than English, there are differences within these languages. For example, the Cisco scenario mentioned above provided French and Spanish versions of its elearning course. Unfortunately, users complaint that the French version was in the Canadian French, while the Spanish version was in the South American Spanish, both of which differ from their European version, thus, creating problems for students from France and Spain respectively. 
Another scholar linked the lack of willingness to participate in WBI to a different language issue, specifically, the non-participation by the Japanese in e-learning is due to how their language is learned and understood (Kawachi, 1999). Kawachi (1999) argued that the nature of the Japanese language, which is developed early in life, is conducive to the right brain learning mode (i.e., visual and memorization skills) as opposed to the left brain mode (i.e., analytic and argumentation skills). This, along with their lack of proficiency in English, leads to a different approach to technology usage. Therefore, the Internet is primarily used for searching and printing-out information for reading or translation off-line, and secondarily for entertainment and games (Kawachi, 1999). Similarly, Zhu et al. (2009) noted that Chinese students had mixed attitudes about online learning and were less likely to use CMC for studying (i.e., learning purposes) in comparison to British students. Due to cultural differences, Chinese students took a different approach than Westernized students when it came to technology usage (Zhu et al., 2009).

Furthermore, the issue of language prompts the need to address the possibility of information overload. WBI can be time consuming with varieties of links to navigate. At times these links or navigational toolbars are not provided sequentially, leaving learners with a sense of navigating through a maze. Also, it has been noted that the amount of work (i.e., labor) and time required by WBI is equivalent, or higher, than that of traditional face-to-face (Palloff \& Pratt, 1999) which can be a tough trade-off to accept, especially when one factors in an adult learner's curriculum, along with other responsibilities they face on a day-to-day basis (Hill, 2002) (see also, Dasgupta \& Gupta, 2009). Learners can easily become overwhelmed by e-mails and discussions, along with other reading assignments in WBI that they become "infoglut" (Hill 2002). Hence, learners must develop a way to manage their schedule, along with instituting management strategies to keep up with assignments and avoid missing important deadlines.

Also, the potential for information overload exists because non-native speakers read at slower speeds than native speakers. For instance, Chinese-English bilinguals read English at 255 words per minute, compared to reading the Chinese language at a rate of 380 words per minute (Wang, Inhoff, \& Chen, 1999). Kawachi (1999) adds that the English reading rate for Japanese is slower than the figure for Chinese, given their English proficiency and learning styles. Even in EDCs such as Europe, language barriers are seen as a hindrance for the rapid adoption of e-learning and WBI. This language barrier results in an increased call for "native-language" content development for local companies not willing or able to adopt English (Barron, 2000). At the same time, language barriers often are a result of cultural pride and cultural identity, which often negatively sensitizes potential users in the adoption process, and at times, puts imported technologies and learning systems at a disadvantage in competing with locally developed e-learning content, providers or systems (Olaniran, 2007a).

\subsection{Technology}

The issue of technology is one that revolves around specific media choice and selection. In general, technology revolves around hardware and software compatibility issues that subsequently become an essential component of any technology discussion. More importantly however, the technology medium has been found to be a way by which globally adopted identities are imposed, hence influencing the socially constructed identity (Gimenez, 2002; Khalil \& Seleim, 2009). 
Scholars in the past and present have devoted significant attention to the issue of media selection and their implications for communication interaction in virtual environments. Different theoretical perspectives have been proposed to gain a better understanding of the role of technology media. In one particular camp, there are those that focus on the media richness - implying that the mechanical and physical characteristics of technology are the primary determinant of communication outcomes (e.g., Daft, Lengel, \& Trevino, 1987; Dennis \& Kinney, 1998; Rice, 1992). Another perspective focuses on the Social Influence perspective, which argues that the social contexts in which technology media are used contribute to the communication outcomes by influencing users' perception (e.g., Dasgupta \& Gupta, 2009; Desanctis, \& Poole, 1994; Fulk, Schmitz, \& Steifield, 1990; Olaniran, 1996). Notwithstanding, the views of the two different camps, it has been found that both technology media and social factors are important and should be taken into consideration when using technology in virtual interaction (Olaniran, 2004; Yoo \& Alavi, 2001). At the same time, different media are able to convey different levels of cues through bandwidth.

Earlier, bandwidth was mentioned and it is an issue germane to the choice of media, or technology, selection in WBI. Bandwidth can limit the choice, or use, of a particular medium for learning purposes. For instance, whether one chooses to use e-mail, discussion board, chat, or videoconferencing would depend on the context and availability of such interfaces. Therefore, while videoconferencing may offer WBI users a high degree of social cues, it requires a significant amount of bandwidth and a faster connection to make it a reality. Consequently, it may not be a viable option in certain regions where access or high bandwidth connections are not available. At the same time, attention to software and hardware compatibility, not to mention file sharing protocols, is an important consideration in the design of content and use of WBI (Olaniran, 2009).

\subsection{Affect}

The choice of a particular technology has different implications in various cultural contexts and thus, affects the use and effectiveness of WBI (Olaniran, 2009; SanchezFranco, et al., 2009). Lee (2002) acknowledged the importance of culture in the selection of a technology medium by examining the differences in email usage between East Asian and Western nations. South East Asian cultures, for example, show cultural differences in the suppression of e-mail, especially when interacting with people of higher status (i.e., power distance) to the extent that they opt for a different medium in order to convey and maintain respect. Thus, technology decisions are made due to the negative, or positive, affect that results from the culture's communication preferences. Therefore, it stands to reason that the choice of a technology medium can also convey a positive or negative cultural affect upon both learner-teacher relations and communication interactions, at large, in WBI (Olaniran, 2001, 2007a, 2009).

Therefore, the concept of affect provides a common determinant for the outcome of technology acceptance and rejection. Affect, defined here, is a culmination of culture, value preferences, language, and power/control, incorporates many factors that greatly influence perception, adoption, and use of technology within diverse cultures. The subject of individual adoption, or behavioral intention to utilize technology (Sykes, Venkatesh, \& Gosain, 2009), is an essential arena of research in the field of ICT; however, it does not always account for the attitudes, values, and beliefs of various cultural groups. This is evident in the case of a commonly accepted technology model, TAM.

The Technology Adoption Model (TAM) is one of the most widely applied and well-verified acceptance models to date, however much of this research has taken place 
in the United States, or in Western Nations, such as the UK, and does not account for cultural variations and language barriers (Lippert \& Volkmar, 2009; Straub, Keil, \& Brenner, 1997). TAM postulates that prior to direct experience, users encapsulate their perceptions of technology within their general beliefs and attitudes regarding technology and thus, its perceived ease of use. However, without a positive direct experience, or even a positive cultural perspective of the technology, it is difficult to expect individuals to subscribe to either its perceived ease of use or perceived usefulness, both of which are the basis of TAM (Sanchez-Franco et al., 2009, Venkatesh \& Davis, 2000).

In further support, Lippert \& Volkmar (2009) state that the results of their cross cultural study suggest that TAM may not predict well across all cultural groups (see also Straub et al., 1997). Therefore, the increased organizational use of cross-cultural virtual teams in addition to the implementation of e-learning solutions in various cultures (e.g., power distant countries, such as Japan), leads to an increased need to understand the affect of the technological innovation. Although TAM is not the only technology adoption model (i.e., Theory of Reason Action (TRA), Theory of Planned Behavior (TPB)) and since its original inception has been adapted to incorporate social forces (Venkatesh \& Davis, 2000), none of these models adequately address the cross-cultural affective factors that encourage culturally appropriate technology adoption (SanchezFranco, 2009; Straub et al., 1997).

The cultural reality of technology adoption is that value preferences affect perception. Although it might be possible to allow employees to influence system development and/or for students to participate in the selection of the learning medium, this process of co-adaptation (Sykes et al., 2009) brings with it assumptions that may not be true for all groups. Some collectivist countries (i.e., South East Asian cultures discussed previously) expect the organization in question, or even instructors, to take control, and for the lines of communication to remain clear in order to maintain respect between the management-employee and teacher-student relationship. Thus, in order to properly implement WBI, it is essential to understand that the affect of culture cannot be separated from the individual, as the cultural effect remains one of the decisive factors of technology and WBI adoption.

\section{Implications}

This paper discusses several cross-cultural challenges that emerge as barriers to effective implementation and successful adoption of what some LEDCs considered to be "Westernized" technologies, in particular, online or e-learning solutions. The cultural challenge is most evident when investigating how culture influences the learning process, and how the human-technology interaction alters communication and interaction. In order to effectively implement WBI and its intended objectives, several cultural implications (e.g., the role of geographic distance and various cultural needs) must be taken into consideration to provide learners with the ability to control how they learn, as well as the learning process in its entirety. Effective implementation of e-learning requires that organizations understand different cultural needs, and the intended objectives of these technologies. This entails giving learners control over how they learn and the process of learning as a whole. To fulfill these objectives, it is imperative that certain pre-requisites are put into practice. 


\subsection{E-learning Solutions in the Workplace}

One key challenge to e-learning in the workplace includes emphasis on organizational goals in terms of how and what organizational leadership intends to accomplish in their respective region and with their employees (Dasgupta \& Gupta, 2009; Olaniran, 2007a; Van Dam \& Rogers, 2002). In essence, this approach ignores cultural implications and insights that employees, or customers, have in controlling how they learn, and the learning process as a whole.

Many organizations have begun to institute web-based or virtual teams composed of individuals in different countries and cultures. Thus, it is important to address specific communication requirements, and cross-cultural challenges, that result from these constructions (Moenaert, Caeldries, Lievens \& Wauters, 2000; Olaniran, 2009; Tapanes, et al., 2009). A climate that fosters effective and efficient cross-cultural communication not only enhances the organization's productivity, but can aid in maintaining relationships. However, for some cultures (e.g., power distant culture) this may prove to be a challenge (Olaniran, 2007a; Olaniran, 2009). In these cultures, face-to-face interactions are viewed as more effective, and at times, essential to maintain levels of respect between superiors and subordinate employees.

While the motivation to use web-based and virtual teams is often economically driven (i.e., cost cutting, speed, and efficiency), there are some key challenges that hinder their effectiveness. Armstrong and Cole (2002) found that while distributed groups sometimes become integrated over time, they nonetheless experience problems due to distance (Crampton, 2002; Olaniran, 1996; 2001a; Solomon, 2001). The lack of face-toface communication also reduces the establishment of trust, and at times, reduces decision making effectiveness, even with the use of ICT technologies such as videoconferencing and constructed virtual work spaces (Kasper-Fuehrer \& Ashkanasy, 2001). Similarly, problems in WBI include misunderstandings and confusion from fragmented communication between group members. Armstrong and Cole (2002) found that national cultures and location, in general, create a dimension of distance that extends beyond geographical boundaries and time zones. Thus, when WBI are implemented and utilized within organizations, or virtual team environments, it is important that their design incorporates appropriate cultural understandings so that members of the organization are not excluded and/or reject the instruction by means of rejecting the technology through which the instruction is delivered.

\subsection{User Needs}

First, research indicates the importance of emphasizing users, or learners' needs (e.g., cultural value orientations and dimensions). Successful integration and accommodation of the different learning needs of various cultures is essential. Rather than accepting a "soft deterministic" view, where technology use is dictated by the structure of the system itself (e.g., its functions follow from its form) (Postman, 1992), organizational leadership must acknowledge that a society, or culture, interacts with - and even shapes - the technologies that are being introduced and implemented. In other words, technology does not guide how it is used; rather, one must consider the variability and dimensions of culture that shape several aspects of the technology in different regions (see Olaniran, 2007a, 2009).

Another implication derived from literature is a move towards promoting equitable outcomes for targeted learners. WBI begins with access to technology and the willingness to use it (Olaniran, 1993). This willingness depends on "technology transfer," 
therefore the benefits of adopting the technology must outweigh the costs (Bozeman, 2000). However, the reverse is often the case when dealing with LEDCs. Subsequently, the issue of access and affordability should be addressed. Providing access to learners in LEDCs is imperative to bridging the digital divide that separates those with frequent access (e.g., EDCs), from those with limited-or no-access (e.g., LEDCs) (Olaniran, 2008). Therefore, to achieve equitable outcomes for targeted learners in LEDCs, access to the technology itself is essential.

Another implication, briefly mentioned, is the promotion of educational and technological literacy that improves socio-economic opportunities in developing nations. Apprehensions emerge from a lack of understanding of how to use technology and a lack of comprehension in regards to the basic commands. In essence, literacy plays a critical role in facilitating the adoption and continued use of Westernized technologies, specifically e-learning (Olaniran, 1993).

One suggestion, aside from providing access to the technology itself, is to develop culture-specific training and tools for targeted learners in different geographic regions. Designers and developers of technology should not limit the elements, structure, and content of WBI to one audience (i.e., those in developed countries).

\section{Discussion}

\subsection{Future Trends}

Although change is inevitable, individuals continue to fear new ideas-such as technological advances-yet, this fear and apprehension can be reduced when cultural implications are recognized by designers, developers, and evaluators. This approach would enhance acceptance and adoption, while tailoring the WBI to the needs of learners, based on cultural implications, hence reducing the fear of new technology. Furthermore, this approach would benefit organizations in the long-run, and circumvent problems of having to retrain, or re-design, the WBI system for each learner. Tailoring the technology to their needs could increase their perceived ease of use (EOU), potentially expediting the adoption process. The utilization of these basic functions will lead to increases in the frequency of use, as well as the duration of continued use of the WBI among learners (Olaniran, 1993).

In general, the challenge is that there does not appear to be a technological and cultural fit in the diffusion of some westernized technology (e.g., Green and Ruhledder, 1995; Mesdag, 2000; Olaniran, 2009). Specifically, from the global e-learning standpoint, the learning content needs to match the needs of users. Although individual learning preferences cannot always be determined, cultural dimensions and differences must be acknowledged, as it is imperative to meet the needs of WBI users to ultimately adopt the technology and ensure continued use (Olaniran, 2009). Thus, the key to resolving cultural problems with technology use, especially within e-learning environments, is to recognize and acknowledge cultural differences, values, structures, and activities in associate technology use within different workplace settings. These differences in cultures are not easily reconciled, and sometimes, the imagined cultural differences create psychological barriers that can be just as real as physical geographic boundaries (Popkewitz, 2001). Within the context of web based environments, it is apparent that cultural implications have been largely ignored and therefore, this has created several cross-cultural challenges 
for the adaptation of some Westernized technologies. The impact of culture can have unintended negative consequences, if ignored.

\subsection{Conclusion}

Implied throughout this paper, cultural implications of specific countries, or nations, must be taken into consideration and incorporated throughout the design and development process of e-learning solutions (Olaniran, 2007a). This will encourage individuals across cultures to re-conceptualize technologies such that they can: (a) speed up adoption of elearning systems and Westernized technologies; (b) alleviate apprehensions associated with educational and technological literacy, including language barriers, information overload, etc.; (c) enhance the frequency of use; and, (d) increase the duration of continued use.

Designers and developers of WBI, such as e-learning, can benefit from this culture-aware approach by creating systems that provide each individual learner with flexible and personalized communication tools, according to their cultural profile (Olaniran, 2008a). Organizations can similarly increase their productivity and the willingness of their employees to utilize these technologies by assuring that e-learning designs reflect diverse cultural values, preferences and norms. Simply focusing upon organizational goals and values are not sufficient in order to encourage cross cultural communication, or diversity, which will ultimately increase idea generation and productivity (Olaniran, 2007b; Kasper-Fuehrer \& Ashkanasy, 2001). Culture represents one of the most significant aspects of an individual's personal and social perspective (Sanchez-Franco et al., 2009). Overall, it is necessary to adopt a more culture-aware approach to design, development, and implementation of the entire e-learning structure and process. However, it is up to designers, organizations, and LEDC countries to work together in order to implement these systems to assure their success.

\section{References}

1. Armstrong, D. J., \& Cole, P. (2002). Managing distances and differences in geographically distributed work groups. In P. Hinds \& S. Kiesler (Eds.), Distributed Work (pp. 167-186).Boston, MA: MIT Press.

2. Attack, L. (2003). Becoming a web-based learner: Registered nurses' experiences. Journal of Advanced Nursing, 44(3), 289-297.

3. Aydin, C., McIsaac, M., \& Johari, A. (2004). The Impact of instructional technology in Turkey. Educational Technology Research \& Development, 52(1), 105-112.

4. Barron, T. (2000, September). E-learning's global migration. Retrieved on August $26 \quad 2005$ from http://www.learningcircuits.org/2000/Sep2000/barron.html.

5. Baruzzo, A., Dattolo, A., Pudota, N., \& Tasso, C. (2009). A general framework for personalized text classification and annotation. In International Workshop on Adaptation and Personalization for Web 2.0, (pp. 31-39), in connection with WMAP 2009, Trento, Italy. Received April 2, 2010, from http://ceurws.org/vol-485/paper4-F.pdf. 
6. Bozeman, B. (2002). Technology transfer and public policy: A review of research and theory. Research Policy, 29, 627-655.

7. Collier, V. P. (1995). Acquiring a second language for school. Directions in language \& Education, 1(4). Retrieved on July, 7, 2008, from http://www.ncela.qwu.edu/pubs/directions/04.htm

8. Crampton, C. D. (2002). Attribution in distributed work groups. . In P. Hinds \& S. Kiesler (Eds.), Distributed Work (pp. 191-212). Boston, MA: MIT Press.

9. Daft, R. L., Lengel, R. H., \& Trevino, L. K. (1987). Message equivocality, media selection, and manager performance: Implications for information systems, MIS Quarterly, 11(3), 355-366.

10. Dasgupta, S., \& Gupta, B. (2009). Espoused organizational culture traits and internet technology adoption. In Americas Conference on Information Systems (AMCIS), Retrieved April 02, 2010, from http://aisel.aisnet.org/amcis2009/586.

11. Davis, F. D. (1986). Technology acceptance model for empirically testing new end user information systems theory and results. Unpublished doctoral Dissertation, Massachusetts Institute of Technology.

12. Davis, F. D. (1989). Perceived usefulness, perceived ease of use and user acceptance of information. MIS Quarterly, 13(3), 319-342.

13. Desanctis, G., \& Poole., M. S. (1994). Capturing the complexity in advanced technology use: Adapative structuration theory. Organization Science, 5(2), 121-147.

14. Dennis, A. R., \& Kinney, S. T. (1998). Testing media richness theory in the new media: The effects of cues, feedback, and task equivocality. Information Systems Research, 9(3), 256-274.

15. Devereaux, M. O., \& Johansen, R. (1994). Global work: Bridging distance, culture, \& time. San Francisco, CA: Jossey-Bass.

16. Dunn, P., \& Marinetti, A. (2007). Beyond localization: Effective learning strategies for cross-culturall e-learning. In In A Edmundson (Ed.), Globalized eLearning Cultural Challenges (pp. 255-266). NY: Idea Group.

17. Ess, C. (2002). Cultures in collision philosophical lessons from computermediated communication. Metaphilosophy, 33(1-2), 229-253.

18. Fulk, J., Schmitz, J., \& Steinfield, C. W. (1990). A social influence model of technology use. In J. Fulk and C. Steinfield, (eds.), Organizations and Communication Technology (pp. 117-140). Newbury Park, CA: Sage.

19. Gimenez, J. (2002). New media and conflicting realities in multinational corporate communication: A case study. IRAL, 40, 323-343.

20. Green, C., \& Ruhleder, K. (1995). Globalization, borderless worlds, and the tower of Babel: Metaphors gone awry. Journal of Organizational Change Management, 8(4), 55-68.

21. Gudykunst, W. B., Chua, E., \& Gray, A. J. (1987). Cultural dissimilarities and uncertainty reduction processes. In M. McLaughlin (Ed.), Communication Yearbook (Vol. 10, pp. 457-469). Beverly Hills, CA: Sage.

22. Hall, E. T. (1976). Beyond culture, New York: Doubleday. 
23. Heaton, L. (2001). Preserving communication context: Virtual workspace and interpersonal space in Japanese CSCW. In C. Ess (Ed.), Culture, Technology, Communication: Towards an Intercultural Global Village (pp. 213-240). Albany, NY: State University of New York Press.

24. Heaton, L. (1998). Preserving communication context: Virtual workspace and interpersonal space in Japanese CSCW. In C. Ess and F. Sudweeks (Eds.) Cultural attitudes towards communication and technology (pp. 163-186). Australia: University of Sydney Press.

25. Henning, E. (2003). I click therefore I am (not)': is cognition 'distributed' or is it 'contained' in boderless e-learning programmes? International Journal of Training and Development, 7(4), 303-317.

26. Hill, J. R. (2002). Overcoming Obstacles and Creating Connections: Community Building in Web-based Learning Environments. Journal of Computing in Higher Education, 14(1), 67-86.

27. Hofstede, G. H. (2001). Culture's consequences: Comparing values, behaviors, institutions, and organizations across nations. Thousand Oaks, CA: Sage.

28. Hofstede, G., \& Bond, M. (1984). Hofstede's culture dimensions: An independent validation using Rokeach's value survey. Journal of Cross-Cultural Psychology, 15(4), 417-433.

29. Hofstede, G. (1980). Culture's consequences. Beverly Hills, CA: Sage.

30. Kasper-Fuehrer, E. C., \& Ashkanasky, N. M. (2001). Communicating trustworthiness and building trust in interorganizational virtual organizations. Journal of Management, 27(3), 235-254.

31. Kawachi, P. (1999). When the sun doesn't rise: Empirical findings that explain the exclusion of Japanese from online global education. Retrieved on January 12, 2008 from http://www.ignou.ac.in/Theme-3/Paul\%20\%20KAWACHI.html.

32. Khalil, O. E. M., \& Seleim, A. (2009). National culture practices and societal information dissemination capacity, (pp. 104-113). Proceedings of the 2009 Conference on Information Science, Technology, and Applications. Retrieved April 02, 2010, from http://portal.acm.org/citation.cfm?id=1551981.

33. Lee, O. (2002). Cultural differences in email use of virtual teams a critical social theory perspective. Cyberpsychology \& Behavior, 5(3), 227-232.

34. Lee, D., \& Johari, A. (2004). Web-Based Instruction in China: Cultural and Pedagogical Implications and Challenges. Educational Technology Research \& Development, 52(1), 101-105. http://search.ebscohost.com.

35. Leu, S. L. (2001). The nine problems that influence the development of network education in China. Retrieved June 7, 2003, from http://www.net.edu.cn/20010829/209762.shtml.

36. Liang, L.M., \& Jian, J.L. (2003). The analysis and reflection of network education in China. Retrieved July 11, 2003, from http://www.net.edu.cn/20030307/3079211.shtml. 
37. Liao, C-H., Huang, W-L. (2009). Community adaptability, computer and internet self-efficacy, and intention of blended e-Learning. International Journal of Society Systems Science, 1(3), 209-226.

38. Lin, G., \& Jiang, C.S. (2003). The current issues facing instructional technology in China. Retrieved June 11, 2003, from http://www.net.edu.cn/20030521 13085234_2.shtml.

39. Liou, D. (2002). The types of network education. Retrieved September 23, 2009, from http://www.net.edu.cn/20020701 /3060450.shtml.

40. Lippert, S. K., \& Volkmar, J. A. (2009). Cultural effects on technology performance and utilization: A comparison of U.S. and Canadian Users. In M. G. Hunter \& F. B. Tan (Eds.) Handbook of research on information management and the global landscape (pp. 346-375). Hershey, PA: IGI Global.

41. McConnell, S. (1998). NGOs and Internet use in Uganda: Who benefits?. In C. Ess \& F. Sudweeks (Eds.) Cultural attitudes towards communication and technology (pp. 104-124). Australia: University of Sydney Press.

42. Mesdag, M. V. (2000). Culture-sensitive adaptation or global standardization - the duration of usage hypothesis, International Marketing Review, 17(1), 74-84.

43. Milstead, J. A. \& Nelson, R. (1998). Preparation for online asynchronous university doctoral course: Lessons learned. Computersin Nursing, 16(5), 247258.

44. Moenaert R. K., Caeldries F., Lievens A., Wauters E., (2000). Communication flows in international product innovation teams, Journal of Product Innovation Management, 17(5), 360-377.

45. Niederhauser, V. P., Bigley, M. B., Hale, J., \& Harper, D. (1999). Cybercases: An innovation in internet education. Journal of Nursing Education, 38(9), 415418.

46. Neuman, P. G., (1998). Risks of e-education. UNESCO Courier, 5(10), 14-16.

47. Olaniran, B. A. (2009, December). Culture, learning styles, and Web 2.0. Interactive Learning Environments, 17(4), 261-271.

48. Olaniran, B. A. (2008). Group decision making in computer-mediated communication as networked communication: Understanding the technology and implications. In M. S. Raisinghani (Ed.). Handbook of research on global information technology management in digital economy (pp. 243-256). Hershey, PA: IGI Global Publishers.

49. Olaniran, B. (2007a). Challenges to implementing e-learning in lesserdeveloped countries. In A. Edmundson (Ed.), Globalized e-learning cultural challenges, (pp. 18-34). Hershey, PA: Idea Group, Inc.

50. Olaniran, B. A. (2007b). Culture and communication challenges in virtual workspaces. In K. St-Amant (Ed.), Linguistic and cultural online communication issues in the global age (pp. 79-92). Hershey, PA: Idea Group, Inc.

51. Olaniran, B. A. (2004). Computer-mediated communication in cross-cultural virtual groups. In Chen, G. M., \& Starosta, W. J. (Eds.), Dialogue among 
diversities, (pp. 142-166). Washington, DC: National Communication Association.

52. Olaniran, B. A. (2001a). The effects of computer-mediated communication on transculturalism. In V. Milhouse, M. Asante, \& P. Nwosu (Eds.) Transcultural Realities (pp. 83-105). Thousand Oaks, CA: Sage.

53. Olaniran, B. A. (2001b). Computer-mediated communication and conflict management process: A closer look at anticipation of future interaction. World Futures, 57, 285-313.

54. Olaniran, B. A. (1996). Social skills acquisition: A closer look at foreign students on college campuses and factors influencing their level of social difficulty in social situations. Communication Studies, 22, 72-88.

55. Olaniran, B. A. (1993). An integrative approach for managing successful computer-mediated communication technological innovation. Ohio Speech Journal, 31, 37-52.

56. Olaniran, B. A., \& Stewart, R. A. (1996). Instructional Practices and classroom communication apprehension: A cultural explanation. Communication Reports, 9, 193-203.

57. Olaniran, B. A., \& Agnello, M. F. (2008). Globalization, educational hegemony, and higher education. Journal of Multicultural Educational Technology, 2(2), 68-86.

58. Palloff, R. M., \& Pratt, K. (1999). Building learning communities in cyberspace: Effective strategies for the online classroom. CA: Jossey-Bass.

59. Popkewitz, T. (2001). Rethinking the political: Reconstituting national imaginaries and producing difference. International Journal of Inclusive Education, 5(2/3), 179-207.

60. Postman, N. (1992). Technopoly. New York: Vintage.

61. Rice, R. (1992). Task analyzability, use of new media, and effectiveness: A multi-site exploration of media richness. Organization Science, 3(4), 475-500.

62. Roach, K. D., \& Olaniran, B. A. (2001). Intercultural willingness to communicate and communication anxiety in International Teaching Assistants. Communication Research Reports, 18, 26-35.

63. Schneckenberg, D. (2009). Understanding the real barriers to technologyenhanced innovation in higher education. Educational Research, 51(4), 411-424.

64. Sanchez-Franco, M. J., Martinez-Lopez, F. J., \& Martin-Velicia, F. A. (2009). Exploring the impact of individualism and uncertainty avoidance in web-based electronic learning: An empirical analysis in European higher education. Computers \& Education, 52(3), 588-598.

65. Selinger, M. (2004). Cultural and pedagogical implications of a global elearning programme. Cambridge Journal of Education, 34(2), 213-229.

66. Solomon, C. M. (2001). Managing Virtual Teams. Workforce, 80(6), 60-65.

67. Straub, D. W., Keli, M., \& Brenner, W. (1997). Testing the technology acceptance model across cultures: A three country study. Information \& Management, 33(1), 1-11. 
68. Sykes, T. A., Venkatesh, V., \& Gosain, S. (2009). Model of acceptance with peer support: A social network perspective to understand employees' system use. MIS Quarterly, 33(2), 371-393.

69. Tapanes, M. A., Smith, G. G., \& White, J. A. (2009). Cultural diversity in online learning: A study of the perceived effects of dissonance in levels of ndividualism/collectivism and tolerance of ambiguity. Internet and Higher Education, 12(1), 26-34.

70. Thurber, B. D., Pope, J. W., \& Stratton, J. (2003). Computer, telecommunications and Western culture. Retrieved September 24, 2009, from, http://www.hoboes.com/html/NetLife/CRIT/CWC.html.

71. Van Dam, N., \& Rogers, F. (2002). E-Learning cultures around the world: Make your globalized strategy transparent. Elearning. 28-33.

72. Vaughan, K., \& MacVicar, A. (2004). Employees' pre implementation attitudes and perceptions to e-learning: A banking case study analysis. Journal of European Industrial Training. 28(5), 400-413.

73. Venkatesh, V. (2000). Determinants of perceived ease of use: Integrating perceived behavioural control, computer anxiety and enjoyment into the technology acceptance model. Information Systems Research, 11(4), 342-365.

74. Venkatesh, V., \& Davis, F. D. (2000). Theoretical extension of the technology acceptance model: Four longitudinal field studies. Management Science, 46(2), 186-204.

75. Wang, J., Inhoff, A. W., Chen, H. (1999). Reading Chinese script: A cognitive analysis. Marwah, NJ: LEA Publishers.

76. Williams, I.M., Warren, H. N., \& Olaniran, B. A. (2009). Achieving Cultural Acquiescence through Foreign Language E-Learning. In M. Chang \& C. Kuo (Eds.), Handbook of Research on Learning Culture and Language via ICTs: Methods for Enhanced Instruction (pp. 88-102). Hershey, PA: Information science.

77. Yoo, Y., \& Alavi, M. (2001). Media and group cohesion: Relative influences on social presence, task participation, and group consensus. MIS Quarterly, 25(3), 371-390.

78. Zhu, C., Valcke, M., \& Schellens, T. (2009). A cross-cultural study of online collaborative learning. Multicultural Education and Technology Journal, 3(1), $33-46$. 